\title{
Phase I clinical trial results of aceneuramic acid for GNE myopathy in Japan
}

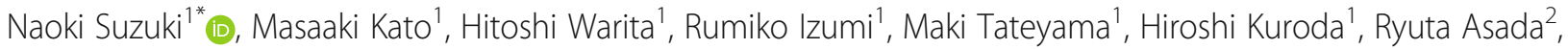
Akifumi Suzuki ${ }^{3}$, Takuhiro Yamaguchi ${ }^{4}$, Ichizo Nishino ${ }^{5}$ and Masashi Aoki ${ }^{*}$

\begin{abstract}
Background: GNE myopathy (distal myopathy with rimmed vacuoles) is a rare intractable muscle disease caused by the mutations in GNE gene, with no therapeutic agents at present. The mutations in GNE (UDP-Nacetylglucosamine 2-epimerase/ $\mathrm{N}$-acetylmannosamine kinase) gene result in a deficiency of the biosynthesis of aceneuramic acid. Aceneuramic acid improves the phenotype of GNE myopathy model mice. We examined the pharmacokinetics and safety of aceneuramic acid therapy in a nonrandomized manner for patients with GNE myopathy for the first time in humans.
\end{abstract}

Methods: This article was based on the world's first Phase I trial and the additional Phase I trial that began at a time when the intermediate results of an overseas Phase II trial were ascertained. In the first trial, conventional tablets without controlled release were administered orally in a single dose of $800 \mathrm{mg}$, in $800 \mathrm{mg} / \mathrm{doses}$ given three times in 1 day, and in $800 \mathrm{mg} /$ doses given three times per day for 5 days. Serum and urinary concentrations of total aceneuramic acid including aceneuramic acid bound to proteins and lipids were measured. Subsequently, administering extended-release tablets to patients with GNE myopathy, we investigated the pharmacokinetics and safety of a single $2000 \mathrm{mg}$ dose, three doses given for 1 day, and three doses per day for 7 days.

Results: The results of the first trial showed no obvious increase in serum concentration after administration. Whereas the amount of aceneuramic acid excreted in the urine generally increased with all given doses, although there were variations among trial subjects. In the second trial, we measured free serum aceneuramic acid levels, and with all doses given there were obvious increases in the levels observed after administration. The degrees of increase were comparable with other studies conducted overseas, and there was no difference based on ethnicity. With regards to urinary excretion, free aceneuramic acid levels showed elevated levels in all patients, and total aceneuramic acid also increased in general, thus we could confirm the absorption of the investigational drug. In respect to safety, while some adverse events including abnormal laboratory test findings were observed, all events were mild and the causal relationship with the investigational drug was ruled out or unlikely.

Conclusion: The elevated serum concentration of aceneuramic acid and safety were confirmed. We decided that the trial could shift to the next level to examine the long-term efficacy and safety for Japanese patients as well.

Trial registration: NCT01236898, UMIN000011532. Registered 9 November 2010.

Keywords: GNE myopathy, Aceneuramic acid, Phase I clinical trial, Ultra-orphan drug

\footnotetext{
*Correspondence: naoki@med.tohoku.ac.jp; aokim@med.tohoku.ac.jp

1 Department of Neurology, Tohoku University Graduate School of Medicine,

1-1 Seiryo-machi, Aoba-ku, Sendai 980-8574, Japan

Full list of author information is available at the end of the article
}

(c) The Author(s). 2018 Open Access This article is distributed under the terms of the Creative Commons Attribution 4.0 International License (http://creativecommons.org/licenses/by/4.0/), which permits unrestricted use, distribution, and reproduction in any medium, provided you give appropriate credit to the original author(s) and the source, provide a link to the Creative Commons license, and indicate if changes were made. The Creative Commons Public Domain Dedication waiver (http://creativecommons.org/publicdomain/zero/1.0/) applies to the data made available in this article, unless otherwise stated. 


\section{Background}

GNE myopathy is a rare intractable disease characterized by atrophy and degeneration of muscles starting from the distal area to the trunk, gradually developing into loss of motor control, with no therapeutic agents and for which treatment is limited to symptomatic treatment [1-5]. In the pathology of affected muscles, variations in the size of the muscle fibers, rimmed vacuoles, and accumulation of amyloid proteins in the muscle fibers can be observed. Myelin bodies and intranuclear inclusion bodies can be seen with electron microscopy. Onset is often in early adulthood. Distal leg muscles, particularly the tibialis anterior muscle, are affected in the early stage of this disease, and foot drop is commonly observed. Initial symptoms at onset include reduced gait speed, gait difficulty, stumbling, and difficulty lifting the toes. As the disease progresses, muscles of the whole lower leg become affected, making gait difficult and the patient becomes wheelchair bound, whereas the quadriceps femoris are less likely to be affected. According to a report by the Registry of Muscular Dystrophy (REMUDY), a registry system of patients with neuromuscular diseases in Japan, the estimated mean period from onset until loss of gait is 21 years; however, there are major individual differences indicating some patients become non-ambulatory in 10 years [3]. Muscle weakness in upper extremities develops later than in lower legs, progressing from the fingers, then in the course of time, to the entire arms. In many patients with gait inability due to GNE myopathy, the neck also becomes unstable, making motion or assistance in motion difficult. In Japan, there have been reports of decreased respiratory function [3], and some patients with severe GNE myopathy with early onset require artificial respiration during the night. In association to reduced muscle strength, problems such as in health management and decreased quality of life (QOL) arise, leading to a need for regular assistance in daily life activities and patients possibly becoming bedridden. A biochemical finding of this disease shows elevated creatinine kinase (CK) in the early stage; however, the degree of elevation is usually slight or within the normal range.

GNE myopathy was reported for the first time around 1980, in Japan [6, 7]. Due to its clinical characteristics, it has also been called distal myopathy with rimmed vacuoles (DMRV). Meanwhile, this condition was reported as a muscular disease with rimmed vacuoles in Israel, subsequently called hereditary inclusion body myopathy (hIBM) as intranuclear tubular fibrous inclusion bodies are seen [8]. Thereafter, a research group in Israel demonstrated autosomal recessive inheritance in the families of Persian Jewish patients with hIBM [9]. They also found the presence of a causative gene on chromosome 9 [9], and mutations in the GNE gene. The GNE gene encodes GNE/
MNK (UDP-acetylglucosamine 2-epimerase/acetylmannosamine kinase), which is an important enzyme involved in the biosynthesis of aceneuramic acid (a typical sialic acid) [10]. GNE/MNK catalyzes two reactions; epimerization from UDP- acetylglucosamine to acetylmannosamine and phosphorylation of the hydroxyl group at the C6 position of acetylmannosamine $[11,12]$.

It has been inferred that the causative gene is the same for hIBM and DMRV, and it was reported that a mutation of the GNE gene was observed in Japanese patients with DMRV [13-16]. To date, more than 150 mutations have been found in patients with hIBM/DMRV; most of those are missense mutations [17]. Recently, muscle diseases caused by these GNE gene mutations have come to be collectively called GNE myopathy [18].

It was thought that the underlying cause of this disease was a mutation of the aceneuramic acid synthesizing enzyme, and in vivo aceneuramic acid mediates in various physiological and pathological processes by binding to terminals of sugar chains of glycoproteins and glycolipids. Therefore, aceneuramic acid replacement therapy was considered. In accordance with this, an attempt was made to create animal models of the disease. GNE gene knockout heterozygous mice were crossed with mice implanted with a mutated form that is common among Japanese patients, and created mouse models in which the endogenous mouse GNE gene was disrupted, thereby expressing only mutant human GNE gene. This mouse model reproduced the disease progression in patients with GNE myopathy very well [19]. Furthermore, they administered $20 \mathrm{mg} / \mathrm{kg} /$ day aceneuramic acid to this mouse model from 10 to 20 weeks postnatal to $54-57$ weeks, and demonstrated the following outcomes; increases in aceneuramic acid concentration and survival rate, decreases in CK concentration, and improvement of muscular histopathology, muscle strength, muscle weight, and motor function [20]. When giving oral doses of $2-\left[{ }^{14} \mathrm{C}\right], 9-\left[{ }^{3} \mathrm{H}\right]$-aceneuramic acid to mice (20 days old) of $1.96 \mathrm{mg} / 100 \mu \mathrm{L} /$ mouse, within 15 min after dosing 95\% of the dosage amount had moved to their intestinal tracts, and $90 \%$ of the dosage amount was absorbed within $6 \mathrm{~h}$, suggesting quick digestive tract absorption of aceneuramic acid [21]. Also, in model mice, when long-term oral doses of $20 \mathrm{mg} / \mathrm{kg} /$ day were given, preventive effects such as increased survival rate, muscle mass, increases in muscle strength, and improved muscle histopathology were exhibited [20]. On the basis of these results, we conducted the world's first phase I clinical trial involving patients with GNE myopathy, and subsequently an additional phase I trial using extendedrelease preparation under development as the therapeutic drug overseas. 


\section{Methods}

\section{Trial overview}

The phase I trial of aceneuramic acid consisted of two trials, both of which were conducted at Department of Neurology, Tohoku University Graduate School of Medicine in accordance with the Good Clinical Practice (GCP) as investigator-initiated trials. The initial trial (Trial-1) and subsequent trial (Trial-2) were conducted after registering with the Clinical Trials.gov (NCT01236898) and the UMIN-CTR (UMIN000011532), respectively. Both trials were conducted with the approval of the institutional review board. [Protocol for trial 1 and 2 (written in English and Japanese) are attached as Additional files 1, 2, 3 and 4]. Subsequently, written informed consent forms explaining the trial were given to potential trial subjects, and then after obtaining written consent screening tests were performed. With verification of eligibility for the trial, patients were enrolled and the trial was commenced. The inclusion criteria for the trial subjects were; patients with definite genetic diagnosis of GNE myopathy, with body weight of $40 \mathrm{~kg}$ or more, aged 20 to 40 years, and without severe complications. Subjects were recruited by self-selection from Patients Association for Distal Myopathies and were allocated in the nonrandomized manner.

\section{Trial design}

Trial-1

Aceneuramic acid was administered in the order of $800 \mathrm{mg}$ single dose, $800 \mathrm{mg}$ dose given three times per day for 1 day, and $800 \mathrm{mg}$ dose given three times per day for 5 days, and then the safety and pharmacokinetics were examined. A total of six patients were involved in the single-dose group $(n=3)$ and the three-times-per-day group $(n=3)$. Of these six patients, three patients were included in the five-day group. With regards to titration of the investigational agent, dose was increased after safety to date was verified. In addition, a data and safety monitoring committee independent of the trial department was established to review the suitability of trial continuation. For Trial-1, non-extended-release $100 \mathrm{mg}$ aceneuramic acid tablets (conventional tablets) developed in Japan were used (Fig. 1a, b). Trial-1 was conducted from November 15, 2011 to June 20, 2011.

\section{Trial-2}

Aceneuramic acid was administered in the order of $2000 \mathrm{mg}$ single dose, $2000 \mathrm{mg}$ dose given three times per day for 1 day, and $2000 \mathrm{mg}$ dose given three times per day for 7 days, then the safety and pharmacokinetics were examined. For this trial, a total of six patients were involved in the single-dose group $(n=3)$ and the three-times-per-day group $(n=3)$. Of these six patients, three patients were included in the seven-day group. Titration of the investigational agent was performed as per
Trial-1. For Trial-2, $500 \mathrm{mg}$ extended-release aceneuramic acid preparations (SA-ER $500 \mathrm{mg}$ ) under development as a pharmaceutical agent overseas were used (Fig. 1c, d). Trial-2 was conducted from October 7, 2013 to December 2, 2011.

In each trial the number of cases that is generally evaluable, and that can be practiced with limited patients was determined.

\section{Measurement of drug concentration-overview}

Blood sampling for serum concentration measurement was performed as follows; using a vacuum blood collection tube containing serum separating medium, collecting approximately $1.5 \mathrm{~mL}$ of blood each time, then after centrifugal separation, the serum was divided into two, placed into two polypropylene tubes and quickly frozen as specimens. Samples for urinary concentration measurement were prepared as follows; measured the precise amount of urine each time slot, from which approximately $10 \mathrm{ml}$ was sampled and divided into two each time, then placed into two polypropylene tubes and frozen as specimens. As aceneuramic acid is also present in the living body, blood and urine samples were collected at times without administration of investigational drug.

In Trial-1, blood sampling for the single dose and three doses per day for 1 day was performed $24 \mathrm{~h}$ prior to administration (initial dose), and 15 and $30 \mathrm{~min}, 1,2$, 4,6 , and $8 \mathrm{~h}$ after the first blood sampling, and immediately prior to administration (initial dose), then 15 and 30 min, 1, 2, 4, 6, 8, and $24 \mathrm{~h}$ after the initial administration. In the three-doses-per-day groups, the second and third doses were administered 6 and $12 \mathrm{~h}$ after the initial administration. On the day of administration, meals were consumed twice, with drug administration (initial dose) given upon fasting, then meals given 4 and $9 \mathrm{~h}$ later. Also on the day before treatment, two meals were consumed at the same times as the treatment day with the same meal content (Fig. 1).

Urine collection for the single-dose and three-doses-per-day groups was divided into four periods; 24 to $20 \mathrm{~h}$ before initial administration, $20 \mathrm{~h}$ to immediately before the administration, immediately before the administration to $4 \mathrm{~h}$ after the administration, and 4 to $24 \mathrm{~h}$ after the administration. The urine volume was measured for each period.

Blood sampling for the three doses per day for five-day group was performed $24 \mathrm{~h}$ before administration (initial dose), 15 and $30 \mathrm{~min}, 1,2,4,6$, and $8 \mathrm{~h}$ after the initial blood collection, immediately before initial administration, then 15 and $30 \mathrm{~min}, 1,2,4,6,8,24,48,72$ and $96 \mathrm{~h}$ after initial administration (before the first dose on day 5), and 15 and $30 \mathrm{~min}, 1,2,4,6,8$, and $24 \mathrm{~h}$ after the first administration on day 5. Meals on the day of start of treatment and day 5 were consumed twice, with 
A

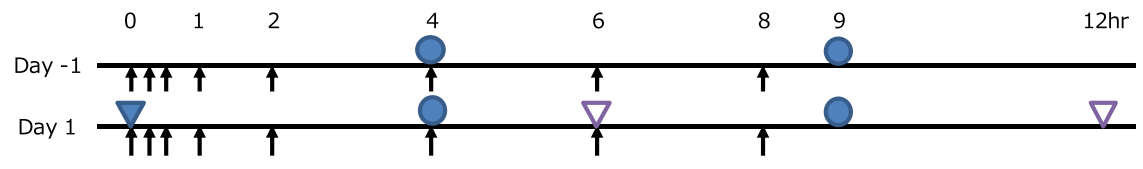

Day 2

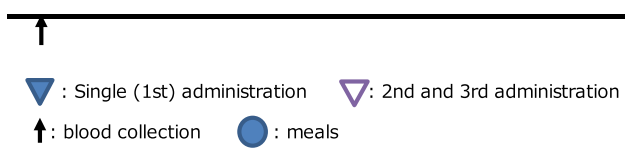

B

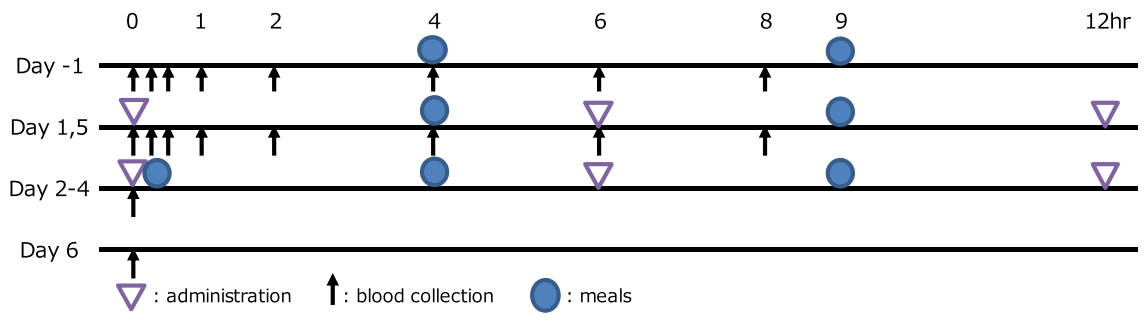

C

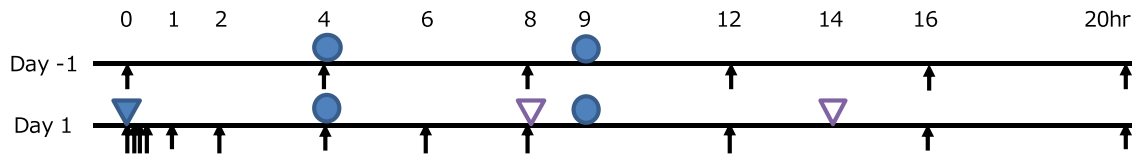

Day 2

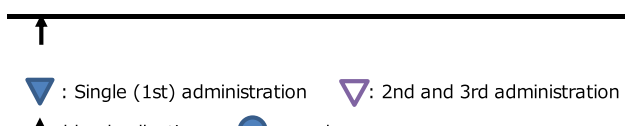

D

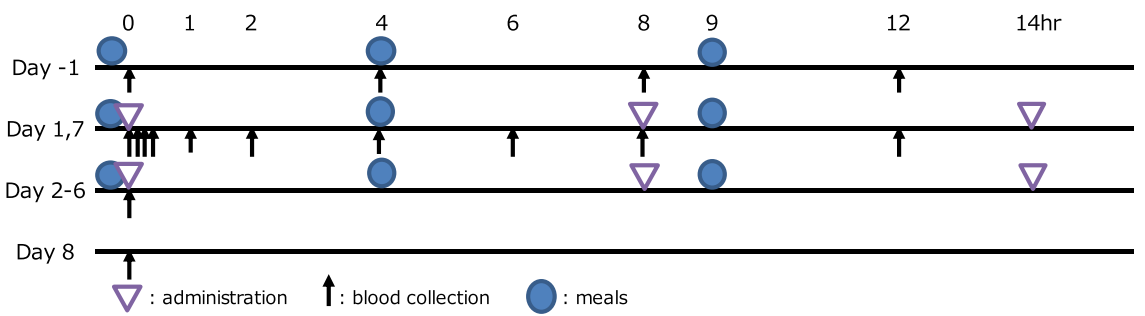

Fig. 1 Timing of administration of test drugs, blood sampling, and meals in Trial-1 and Trial-2. a. Single administration and three-times-per-day administration for Trial-1. b. Three times per day for 5-day administration for Trial-1. c. Single administration and three-times-per-day administration for Trial-2. d. Three times per day for 7-day administration for Trial-2. Triangle indicates the timing of administration. Arrows indicate the timing of blood collection. Stars indicate meals. Since aceneuramic acid also exists intravitally, we measured it during the day before the start of administration as well

the initial dose given upon fasting, then meals given 4 and $9 \mathrm{~h}$ after the administration. The second and third doses were given 6 and $12 \mathrm{~h}$ after the initial administration. On the day before treatment, two meals were consumed at the same time as the day of initiation of treatment with the same meal content. On days 2, 3, and 4 of treatment, meals were given immediately after the first dose of the day, then 4 and $9 \mathrm{~h}$ after the first administration (Fig. 1).

For the three doses per day for five-day group, urine collection was divided into six periods, i.e. 24 to $20 \mathrm{~h}$ before administration, $20 \mathrm{~h}$ to immediately before administration, immediately before administration to $4 \mathrm{~h}$ after the administration and, 4 to $24 \mathrm{~h}$ after the administration on day 1 ; immediately before the first administration to $4 \mathrm{~h}$ after the first administration on day 5 , and 4 to $24 \mathrm{~h}$ after the first administration on day 5 . The urine volume was measured for each period.

Measurements of total aceneuramic acid and total $\mathrm{N}$-glycolylneuraminic acid were performed at LSI Medience Corporation using LC/MS/MS methods established by the same company. The quantitative ranges were 1 to $2500 \mu \mathrm{g} / \mathrm{mL}$ in serum and 1 to $10,000 \mu \mathrm{g} / \mathrm{mL}$ in urine for total aceneuramic acid, 1 to $2500 \mu \mathrm{g} / \mathrm{mL}$ in serum 
and 1 to $2500 \mu \mathrm{g} / \mathrm{mL}$ in urine for total $N$-glycolylneuraminic acid.

In Trial-2, blood sampling for the single dose and three doses per day for 1 day was performed $24 \mathrm{~h}$ prior to administration (initial dose), 4, 8, 12, 16, and $20 \mathrm{~h}$ after the first blood sampling, and immediately prior to administration (initial dose), then 10, 20, $30 \mathrm{~min}, 1,2$, 4, $6,8,12,16,20$, and $24 \mathrm{~h}$ after the initial administration. In the three doses per day groups, the second and third doses were administered 8 and $14 \mathrm{~h}$ after the initial administration. On the day of administration, meals were consumed twice, with drug administration (initial dose) given upon fasting, then meals given 4 and $9 \mathrm{~h}$ later. Also on the day before treatment, two meals were consumed at the same time as the treatment day with the same meal content (Fig. 1).

Urine collection for the single-dose and three-doses -per-day groups was divided into four periods; 24 to $20 \mathrm{~h}$ before initial administration, $20 \mathrm{~h}$ to immediately before the administration, immediately before the administration to $4 \mathrm{~h}$ after the administration, and 4 to $24 \mathrm{~h}$ after the administration. The urine volume was measured for each period.

Blood sampling for the three doses per day for 7 days group was performed $24 \mathrm{~h}$ before administration (initial dose), 4, 8, and $12 \mathrm{~h}$ after the initial blood collection, immediately before initial administration, then 10,20 , $30 \mathrm{~min}, 1,2,4,6,8,12,24,48,72,96,120$, and $144 \mathrm{~h}$ after initial administration (before the first dose on day 7), and 10, 20, $30 \mathrm{~min}, 1,2,4,6,8,12$, and $24 \mathrm{~h}$ after the first administration on day 7 . The second and third doses were given 8 and $14 \mathrm{~h}$ after the initial administration. The meals on the treatment days were consumed three times; before the first administration, and 4 and $9 \mathrm{~h}$ after the administration. On the day before treatment, the same meal content was consumed at the same times as the days of treatment (Fig. 1).

For three doses per day for seven-day group, urine collection was divided into six periods, i.e. 24 to $20 \mathrm{~h}$ before administration, $20 \mathrm{~h}$ to immediately before administration, immediately before administration to $4 \mathrm{~h}$ after the administration, 4 to $24 \mathrm{~h}$ after the administration, immediately before the first administration to $4 \mathrm{~h}$ after the first administration on day 7 , and 4 to $24 \mathrm{~h}$ after the first administration on day 7 . The urine volume was measured for each period.

Measurements were taken using LC/MS/MS methods established by Intertek Pharmaceutical Services Bioanalytical LCMS. The quantitative ranges were 0.0400 to $20.0 \mu \mathrm{g} / \mathrm{mL}$ in serum, 1.00 to $200 \mu \mathrm{g} / \mathrm{mL}$ in urine for free aceneuramic acid, and 5.00 to $400 \mu \mathrm{g} / \mathrm{mL}$ in urine for total aceneuramic acid.

Details underlying the reason that total aceneuramic acid was measured in Trial-1, and serum free aceneuramic acid and urinary free- and total- aceneuramic acid were measured in Trial-2 will be explained later.

\section{Drug concentration analysis methods Serum aceneuramic acid concentration}

Due to the small number of subjects in this trial, changes in the serum aceneuramic acid concentration for each individual patient were presented in figures.

The pharmacokinetics parameters of aceneuramic acid $\left(\mathrm{AUC}_{\mathrm{t}}, \mathrm{AUC}_{\infty}, \mathrm{C}_{\max }, \mathrm{T}_{\max }, \lambda_{\mathrm{z}}, \mathrm{MRT}_{\mathrm{t}}, \mathrm{T}_{1 / 2}, \mathrm{CL}\right.$, and $\mathrm{V}_{\mathrm{d}}$ ) were calculated for each patient based on serum concentrations of the day before administration (start), the day of and day following administration (start), then for repeated doses, on the final day of administration and the following day. With these data, the summary statistics were calculated for each treatment group. Moreover, the differences in serum aceneuramic acid concentrations were calculated at each point of time corresponding to 1 day from the day before administration (start) and after administration (or during administration). On the basis of these differences, the pharmacokinetics parameters for aceneuramic acid were calculated for each patient, and the summary statistics for each group were calculated. In addition, for the day before administration (start), when the previous values corresponding to the administration day were not measured, the mean value obtained prior to the start of treatment was used as the previous value.

\section{Urine aceneuramic acid concentration}

The amount of aceneuramic acid excreted in the urine was calculated from urine concentration of aceneuramic acid and volume of urine. Furthermore, the amount excreted in the urine was compared in each patient for 1 day from the day before treatment (start), 1 day from the day of administration (start), then for repeated doses, the time period corresponding to 1 day after the final day of administration (0 to 4 , and 4 to $24 \mathrm{~h}$ ), as well as the $24 \mathrm{~h}$ for this time period combined.

\section{Safety}

Safety was confirmed based on medical examinations, physical tests, clinical tests (blood count, blood biochemistry, and urine), electrocardiography, and echocardiography. Upon occurrence of adverse events, the details, severity, seriousness, causal relationship with the investigational agent, and outcomes were noted.

\section{Statistical analysis}

SAS(version 9.1.3 for Trial-1, version 9.3 for Trial-2, SAS Institute Japan Ltd.)was used for statistical analysis. Especially pharmacokinetic parameters were analyzed by 
non-compartment model using Phoenix WinNonlin (ver. 6.2, Pharsight Corporation, USA).

\section{Results}

\section{Demographic statistics}

In Trial-1, for a total of six patients with GNE myopathy, a single dose $(n=3)$ and three doses per day for 1 day $(n=3)$ were given. The patients included three men and three women with a mean age of 33 years (range; 23 to 39 years), the mean height of $167 \mathrm{~cm}$ (range; 153 to $179 \mathrm{~cm}$ ), and the mean body weight of $57.7 \mathrm{~kg}$ (range; 43.3 to $78.0 \mathrm{~kg}$ ). Of these six patients, three patients (a man and two women) received administration of the investigational agent for 5 days (Table 1 ).

In Trial-2, for a total of six patients with GNE myopathy, a single dose $(n=3)$ and three doses per day for 1 day $(n=3)$ were given. The patients included three men and three women with a mean age of 31 years (range; 25 to 37 years), the mean height of $170 \mathrm{~cm}$ (range; 160 to $181 \mathrm{~cm}$ ), and the mean body weight of $54.2 \mathrm{~kg}$ (range; 40.1 to $67.9 \mathrm{~kg}$ ). Of these six patients, three patients (two men and a woman) received administration of the investigational agent for 7 days (Table 1).

Figure 2 shows a flow diagram of the progress through the two phase I trials.

Trial-1

\section{Changes in serum aceneuramic acid concentration}

In Trial-1, $100 \mathrm{mg}$ conventional aceneuramic acid tablets developed in Japan were used. For the aceneuramic acid concentration, total aceneuramic acid combining protein- and lipid-bound bodies with free bodies were measured.

First, the changes in serum total aceneuramic acid concentrations when aceneuramic acid $800 \mathrm{mg}$ was administered in a single dose and three doses for 1 day. Physiologically present aceneuramic acid was also measured; however, there was no increase in serum concentration observed after administration of aceneuramic acid (Fig. 3).

We then measured the changes in serum total aceneuramic acid concentrations when aceneuramic acid $800 \mathrm{mg}$ was administered in three doses per day for 5 days. Measurement points were; immediately before the first administration, and 15 and $30 \mathrm{~min}, 1,2,4,6,8$, and $24 \mathrm{~h}$ after the first administration on day 1 and day 5 . Measurements were also performed at corresponding times on the day before the starting day, and immediately before the first administration on day 3 and day 4 . As with the single dose and three doses for 1 day groups, physiologically present aceneuramic acid was also measured; however, there was no obvious increase in serum concentration observed after aceneuramic acid administration (Fig. 3). Therefore, we were unable to examine pharmacokinetics parameters.

Thus, when aceneuramic acid $800 \mathrm{mg}$ was administered in three doses per day for 5 days, an increase in serum total aceneuramic acid concentration was not observed after administration of the investigational agent.

\section{The amount of aceneuramic acid excreted in the urine for Trial-1}

We examined the changes in total amount of aceneuramic acid excreted in the urine when aceneuramic acid $800 \mathrm{mg}$ was administered in a single dose and three doses for 1 day. Excluding one patient (subject No. 1), the results showed an increased amount of aceneuramic acid excreted in the urine for $24 \mathrm{~h}$ after administration (Fig. 4).

Next, we examined the changes in total amount of aceneuramic acid excreted in the urine when aceneuramic acid $800 \mathrm{mg}$ was administered in three doses per day for 5 days. The results showed an increased amount

Table 1 Subject demographics and baseline characteristics

\begin{tabular}{|c|c|c|c|c|c|c|c|c|}
\hline \multirow[t]{2}{*}{ Demographics } & \multicolumn{4}{|l|}{ Trial-1 } & \multicolumn{4}{|l|}{ Trial-2 } \\
\hline & $\begin{array}{l}800 \mathrm{mg} \times 1 \\
n=3\end{array}$ & $\begin{array}{l}800 \mathrm{mg} \times 3 \\
n=3\end{array}$ & $\begin{array}{l}\text { Total } n \\
=6\end{array}$ & $\begin{array}{l}800 \mathrm{mg} \times 3 \times \\
5 \text { days } n=3\end{array}$ & $\begin{array}{l}2,000 \mathrm{mg} \times 1 \\
n=3\end{array}$ & $\begin{array}{l}2,000 \mathrm{mg} \times 3 \\
n=3\end{array}$ & $\begin{array}{l}\text { Total } n \\
=6\end{array}$ & $\begin{array}{l}2,000 \mathrm{mg} \times 3 \times \\
7 \text { days } n=3\end{array}$ \\
\hline Age in years, mean (STDV) & $32.0(8.2)$ & $33.0(5.2)$ & $\begin{array}{l}32.5 \\
(6.2)\end{array}$ & $36.7(5.8)$ & $32.0(5.6)$ & $29.3(6.7)$ & $\begin{array}{l}30.7 \\
(5.7)\end{array}$ & $32.7(6.1)$ \\
\hline Sex (male), n (\%) & $2(66.7)$ & $1(33.3)$ & $3(50.0)$ & $1(33.3)$ & $2(66.7)$ & $1(33.3)$ & $3(50.0)$ & $2(66.7)$ \\
\hline Height cm, mean (STDV) & $172.0(8.2)$ & $161.7(11.7)$ & $\begin{array}{l}166.8 \\
(10.7)\end{array}$ & $163.3(14.6)$ & $171.0(8.7)$ & $169.7(10.6)$ & $\begin{array}{l}170.3 \\
(8.7)\end{array}$ & $172.3(8.6)$ \\
\hline Weight kg, mean (STDV) & $61.6(14.3)$ & $53.8(9.8)$ & $\begin{array}{l}57.7 \\
(11.7)\end{array}$ & $59.7(18.2)$ & $56.7(4.2)$ & $51.6(14.5)$ & $\begin{array}{l}54.2 \\
(9.9)\end{array}$ & $61.3(10.3)$ \\
\hline BMI in $\mathrm{kg} / \mathrm{m}^{2}$, mean (STDV) & $20.7(4.4)$ & $20.6(3.0)$ & $\begin{array}{l}20.6 \\
(2.9)\end{array}$ & $22.0(3.3)$ & $19.6(3.6)$ & $17.7(3.3)$ & $\begin{array}{l}18.7 \\
(3.2)\end{array}$ & $20.7(3.5)$ \\
\hline Race, n (\%) Japanese & $3(100)$ & $3(100)$ & $6(100)$ & $3(100)$ & $3(100)$ & $3(100)$ & $6(100)$ & $3(100)$ \\
\hline $\begin{array}{l}\text { Disease duration in years, } \\
\text { mean (STDV) }\end{array}$ & $10.4(4.4)$ & $12.1(5.0)$ & $\begin{array}{l}11.3 \\
(4.3)\end{array}$ & $13.2(5.1)$ & $11.7(3.5)$ & $10.4(8.4)$ & $\begin{array}{l}11.1 \\
(5.8)\end{array}$ & $11.6(5.0)$ \\
\hline
\end{tabular}




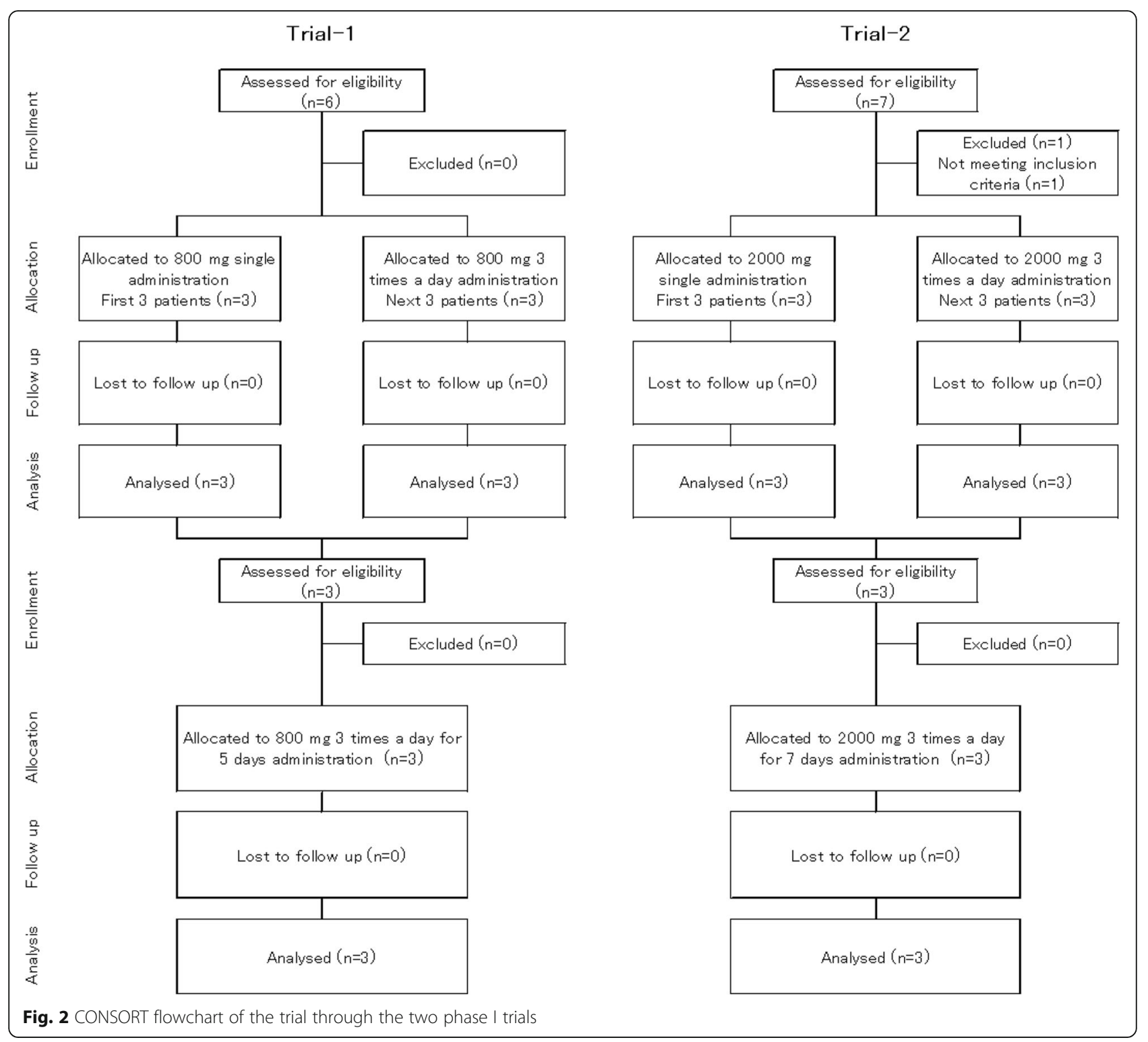

of aceneuramic acid excreted in the urine for $24 \mathrm{~h}$ after administration for all three patients (Fig. 4).

\section{Trial-2}

\section{Changes in serum aceneuramic acid concentration}

In Trial-2, 500 mg extended-release tablets of aceneuramic acid were used. For the aceneuramic acid concentration, free aceneuramic acid unbound to proteins and lipids was measured.

The changes in serum free aceneuramic acid concentrations when aceneuramic acid $2000 \mathrm{mg}$ was administered in a single dose and three doses for 1 day were measured. Physiologically present free aceneuramic acid in serum was also measured, which showed that there were an obvious increase in serum aceneuramic acid concentration levels after administration in all three patients with the single dose and the three patients with three doses for 1 day (Fig. 5). In the mean value of three patients with a single dose, the increases in serum aceneuramic acid concentration levels were observed from $20 \mathrm{~min}$ after the administration, peaked approximately 1-4 $\mathrm{h}$ after the administration with three times the values without administration. The increased concentration levels were also seen at $8 \mathrm{~h}$ after administration, compared to without administration. The mean value of three patients given three doses for 1 day also increased from $30 \mathrm{~min}$ after the administration. In this group, peaks of the concentration levels were observed twice, at approximately $4 \mathrm{~h}$ and $20 \mathrm{~h}$ after the administration, and this might have been due to few measurement times. The value in the first peak was more than approximately twice that without administration, and a higher value 

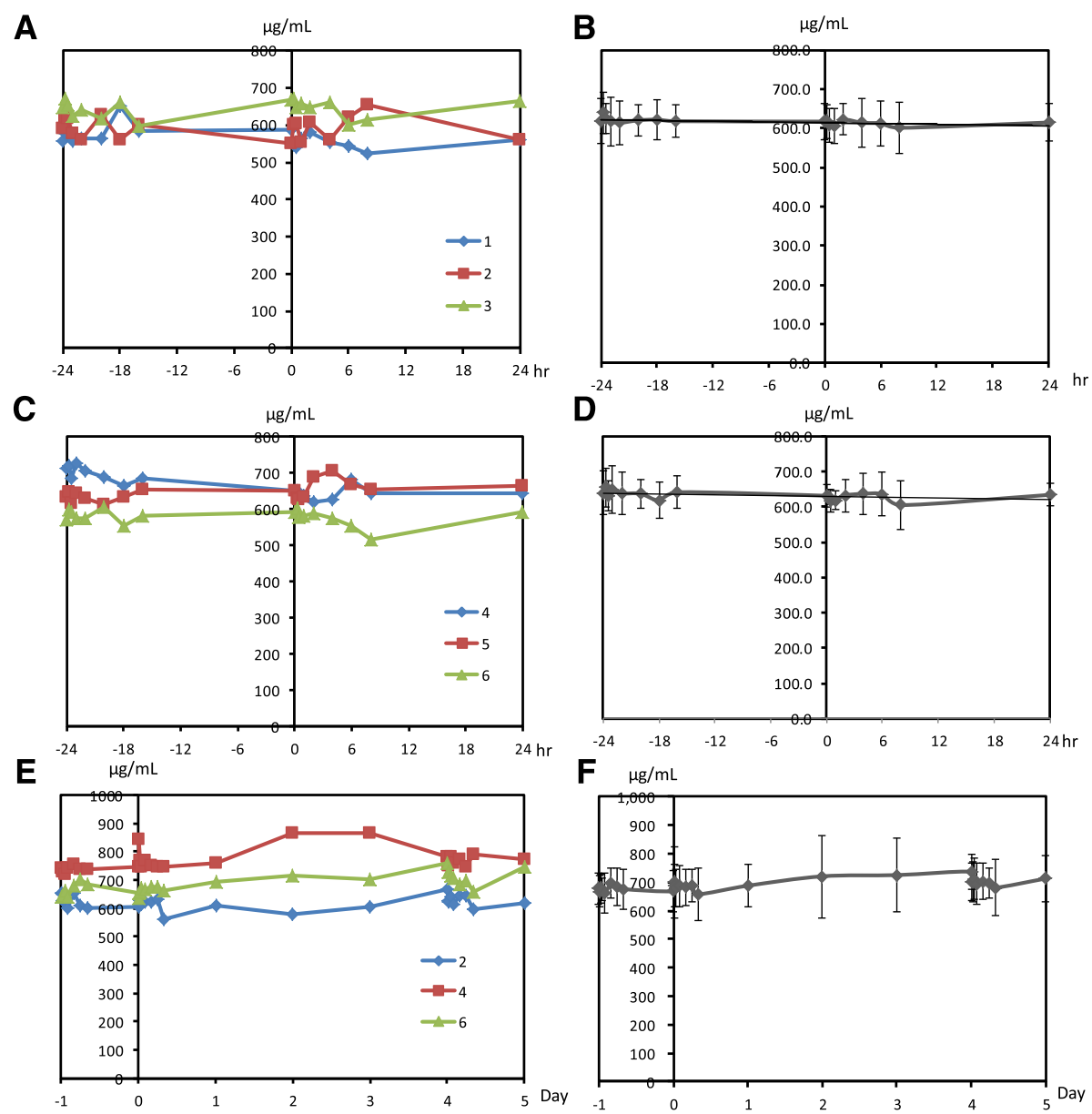

Fig. 3 Changes in serum total aceneuramic acid concentrations measurement (Trial-1). In Trial-1, total aceneuramic acid that is aceneuramic acid combined with protein or lipid as well as free aceneuramic acid was measured. Since physiologically existing total aceneuramic acid is also measured, no increase in the concentration after administration was observed in each case. a. Single administration trial for each individual subject (subject numbers 1 to 3). -24 to $0 \mathrm{~h}$ (un-administered), 0 to $24 \mathrm{~h}$ (administered). b. Average of A. mean changes \pm standard deviation, $n=$ 3 for each group. c. Three-times-per-day administration trial for each individual subject (subject numbers 4 to 6 ). -24 to 0 h (un-administered), 0 to $24 \mathrm{~h}$ (administered). d. Average of C. mean changes \pm standard deviation, $n=3$ for each group. e. Three-times-per-day administration for 5 -day trial for each individual subject (subject numbers 2, 4 and 6). - 1 to 0 Day (un-administered), 0 to 5 Day (administered). f. Average of E. mean changes \pm standard deviation, $n=3$ for each group

than the first peak was maintained at $24 \mathrm{~h}$ after administration. Further, the mean value of serum free aceneuramic acid concentration in the six patients in both the single-dose and three-doses-per-day groups on the day prior to administration to immediately prior to administration was $0.136 \pm 0.019 \mu \mathrm{g} / \mathrm{mL} \quad(n=42$, mean value \pm standard deviation).

We also examined the changes in serum free aceneuramic acid concentrations when aceneuramic acid $2000 \mathrm{mg}$ was administered in three doses per day for 7 days. The investigational agent was administered for 7 days, with the first dose given in the morning of each day, then the second and third doses given 8 and $14 \mathrm{~h}$ after the first administration. While there were major individual differences, obvious increases in serum free aceneuramic acid concentration after administration were found in all three patients, and the increased concentration levels were maintained for the period of 7 days. Although the peaks of the trough values differed depending on the individual patient, the peaks were observed within 7 days. In the mean value for three patients, this increase was seen from 2 hours after the start of treatment, and serum free aceneuramic acid trough concentration was maintained at about 2.8 times that of before the start of treatment, from day 2 to the following morning of day 7 . On day 7 of administration, the concentration of serum free aceneuramic acid was about 2.4 times on average that of before the start of treatment. (Fig. 5).

In Trial-2, we calculated pharmacokinetic parameters based on serum concentration up to $24 \mathrm{~h}$ after administration for a single dose. We calculated Cmax, Tmax, AUCt, and MRT for the pharmacokinetic parameter 


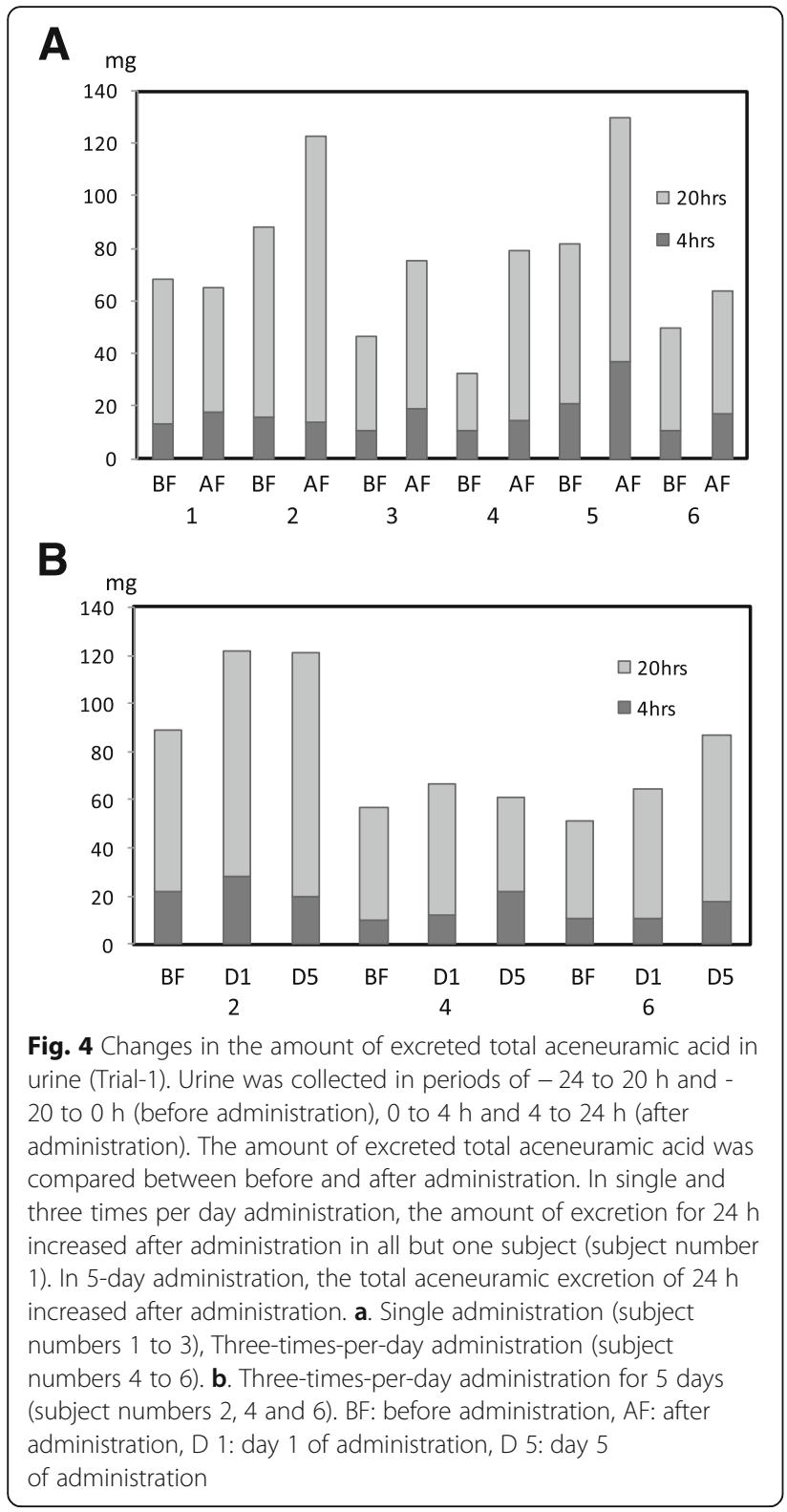

(Table 3) for three doses in a day and for three doses per day for 7 days, 8 hours after the first administration of the day (just before the second administration) based on serum concentration. Cmax was 0.093 to $0.624 \mu \mathrm{g} /$ $\mathrm{mL}$, and Tmax was also 1 to $8 \mathrm{~h}$ for the single-dose and for the first day of the three-doses-per-day groups, so there were individual differences. The T1/2 for single-dose administration was 2 to $7 \mathrm{~h}$, so there was individual difference after all and it was relatively shorter. In this way, we could calculate some free aceneuramic acid pharmacokinetic parameters; however, due to the major individual differences, it was thought that there was not much significance in conducting detailed examinations, in the present report we only examined on the basis of the changes observed and the mean values for each patient. We summarized the pharmacokinetic parameters of each subject in Trial-2 (Table 2).

\section{The amount of aceneuramic acid excreted in the urine for Trial-2}

We examined the changes in the amount of total and free aceneuramic acid excreted in the urine when $2000 \mathrm{mg}$ extended-release aceneuramic acid tablets were administered in a single dose and three doses for 1 day. The results showed an increased amount of free aceneuramic acid excreted in the urine for $24 \mathrm{~h}$ after administration. The amount of total aceneuramic acid excreted in the urine for $24 \mathrm{~h}$ after the administration also generally increased (Fig. 6).

Next, we examined the changes in the amount of total and free aceneuramic acid excreted in the urine when $2000 \mathrm{mg}$ aceneuramic acid tablets were administered in three doses per day for 7 days. The results showed an increased amount of free aceneuramic acid excreted in the urine for $24 \mathrm{~h}$ after administration for all three patients (Fig. 6).

\section{Safety}

In Trial-1, adverse events were observed in all patients; however, all events were mild and non-serious. The causal relationships with the investigational agent were deemed 'unlikely' or 'no relationship.' Among them, when severity was judged based on the criteria of CTCAE v4.0 - JCOG, only "urinary tract infection" and "gastroenteritis viral" found in one case corresponded moderately, the others were mild adverse events.

Overall, there were 31 adverse events observed with the single-dose group and three-doses-per-day group. The adverse events included decreased blood albumin, total protein, and hematocrit levels (three cases each); decreased albumin-globulin ratio, thrombocytopenia, and positive result of urine protein (two cases each), and others (one case each). With the five-day treatment group, there were 22 adverse events observed, including 3 cases of decreased blood protein levels, 2 cases of decreased total protein levels, and 1 case each for other events (Table 3).

In Trial-2, adverse events were observed in four patients out of six patients given a single dose or three doses for 1 day, and in two out of the three patients given three doses per day for 7 days. All adverse events were mild and non-serious. They were all mild adverse events, after evaluating the severity of these based on CTCAE v4.0 - JCOG criteria. The causal relationships with the investigational agent were all deemed to be 'no relationship.' Overall, there were four adverse events observed in three-doses-per-day group, including two cases of increased triglycerides, and one each case of eczema 
A

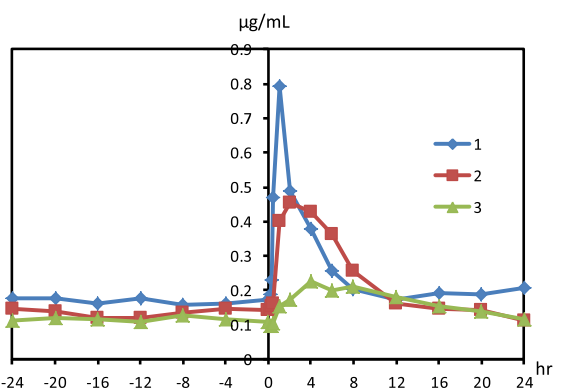

C

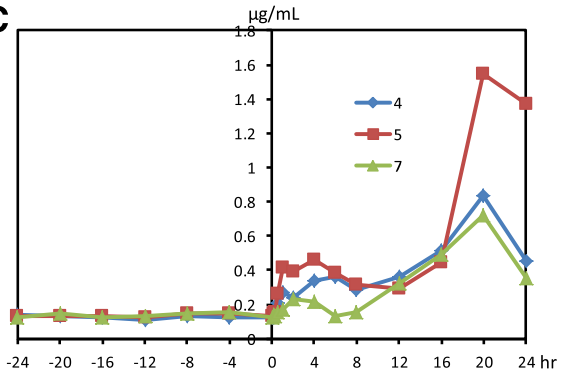

E $\mu \mathrm{g} / \mathrm{mL}$

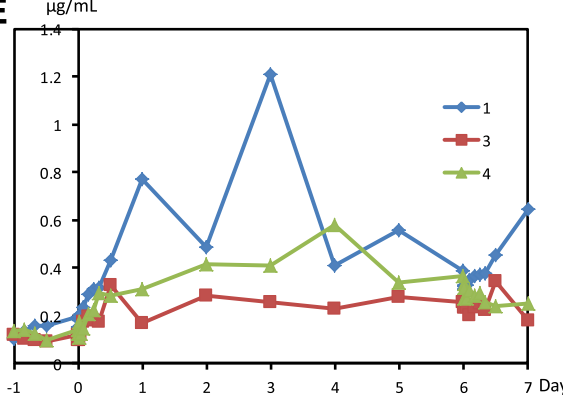

B

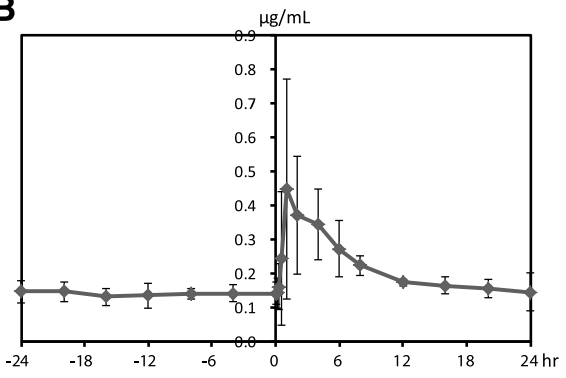

D
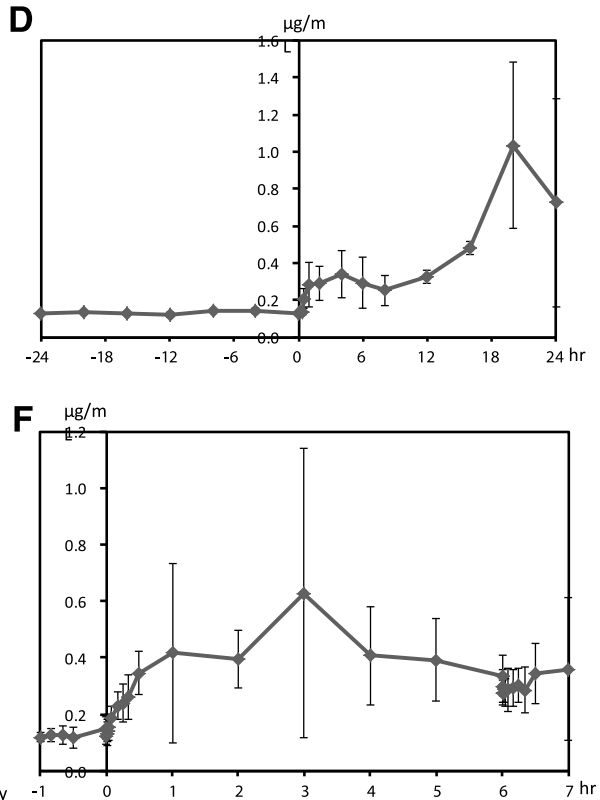

Fig. 5 Changes in serum free aceneuramic acid concentrations measurement (Trial-2). In Trial-2, serum free aceneuramic acid not bound to protein or lipid was measured, focusing on concentration increase due to investigational drug administration. Tough physiologically existing free aceneuramic acid is also measured, the concentration after administration clearly increased in each case. a. Single administration for each individual subject. b. Single administration on average. Mean changes \pm standard deviation, $n=3$ for each group. $\mathbf{c}$. Three-times-per-day administration for each individual subject. In three-times-per-day administration, the $2 \mathrm{nd}$ and $3 \mathrm{rd}$ administration is 8 and $14 \mathrm{~h}$ after the 1 st administration. $\mathbf{d}$. Three-times-per-day administration on average. Mean changes \pm standard deviation, $n=3$ for each group. e. Three times per day for 7-day administration for each individual subject. f. Three times per day for 7-day administration on average. Mean changes \pm standard deviation, $n=3$ for each group. In all cases of 7-day administration though individual variations were large, a clear increase in concentration was observed during administration and was maintained for 7 days. The peak of the trough value was different in each subject but was confirmed within 7 days

and increased $\mathrm{LDH}$, respectively. With the seven-day treatment group, there were two cases of adverse events observed overall, including one case of elevated triglycerides and one case of fall (Table 3).

\section{Discussion}

We conducted the trials to investigate the pharmacokinetics and safety of aceneuramic acid for patients with GNE myopathy (distal myopathy with rimmed vacuoles), administering in a single-dose and three doses for 1 day/ 5 days. A total of six patients participated in the present trial. We first examined the safety and pharmacokinetics of $800 \mathrm{mg}$ of aceneuramic acid administered in a single dose (three patients) and three doses for 1 day (three patients). Subsequently, one patient from the single-dose group and two patients from the three doses for 1 day group (a total of three patients) received $800 \mathrm{mg}$ of aceneuramic acid three times/day for 5 days, and the safety and pharmacokinetics were similarly examined. In this trial, conventional $100 \mathrm{mg}$ tablets developed in Japan were used, and total aceneuramic acid concentration levels including protein- and lipid-bound aceneuramic acid were measured. However, obvious increases in the serum concentration were not seen after administration of $800 \mathrm{mg}$ in a single dose and three doses for 1 day $/ 5$ days. Accordingly, we were unable to calculate the pharmacokinetics parameters based on these results. Meanwhile, the amount of excreted aceneuramic acid in 
Table 2 Aceneuramic acid pharmacokinetic parameters in Trial-2

\begin{tabular}{|c|c|c|c|c|c|c|c|c|c|c|c|c|}
\hline \multirow[b]{2}{*}{ Subject No. } & \multicolumn{3}{|c|}{$2,000 \mathrm{mg} \times 1$} & \multicolumn{3}{|c|}{$2,000 \mathrm{mg} \times 3$} & \multicolumn{6}{|c|}{$2,000 \mathrm{mg} \times 3 \times 7$ days } \\
\hline & 1 & 2 & 3 & 4 & 5 & 7 & 1 & & 3 & & 4 & \\
\hline & & & & & & & 1st day & 7th day & 1st day & 7th day & 1st day & 7th day \\
\hline$C_{\max }(\mu \mathrm{g} / \mathrm{mL})$ & 0.624 & 0.319 & 0.106 & 0.233 & 0.335 & 0.095 & 0.172 & 0.285 & 0.093 & 0.146 & 0.169 & 0.234 \\
\hline $\mathrm{T}_{\max }(\mathrm{h})$ & 1 & 2 & 4 & 6 & 4 & 2 & 6 & 0 & 4 & 6 & 8 & 0 \\
\hline$A \cup C,(\mu \mathrm{g} \cdot \mathrm{h} / \mathrm{ml})$ & 2.074 & 2.328 & 1.271 & 1.343 & 1.991 & 0.346 & 1.009 & 1.731 & 0.544 & 1.029 & 0.549 & 1.276 \\
\hline MRT (h) & 5.288 & 5.122 & 9.095 & 4.609 & 4.075 & 3.288 & 4.799 & 4.122 & 4.644 & 4.129 & 5.759 & 3.842 \\
\hline$\lambda_{z}(/ h)$ & 0.098 & 0.303 & 0.168 & N.A. & N.A. & N.A. & N.A. & N.A. & N.A. & N.A. & N.A. & N.A. \\
\hline $\mathrm{T}_{1 / 2}$ (hrs) & 7.089 & 2.291 & 4.138 & N.A. & N.A. & N.A. & N.A. & N.A. & N.A. & N.A. & N.A. & N.A. \\
\hline $\mathrm{CL}(\mathrm{mL} / \mathrm{h})$ & 819 & 846 & 1530 & N.A. & N.A. & N.A. & N.A. & N.A. & N.A. & N.A. & N.A. & N.A. \\
\hline $\mathrm{Vd}(\mathrm{ml})$ & 8376 & 2795 & 9136 & N.A. & N.A. & N.A. & N.A. & N.A. & N.A. & N.A. & N.A. & N.A. \\
\hline$A \cup C_{0-\infty}(\mu \mathrm{g} \cdot h / m L)$ & 2.279 & 2.367 & 1.318 & N.A. & N.A. & N.A. & N.A. & N.A. & N.A. & N.A. & N.A. & N.A. \\
\hline
\end{tabular}

The baseline aceneuramic acid concentrations for each subject were subtracted from the corresponding concentrations for that point. For time points in which there is no corresponding baseline concentration, mean baseline concentration from that subject was subtracted to determine the net increase in aceneuramic concentration

Cmax, Tmax, AUCt, MRT are calculated based on the data before 2 nd administration ( $8 \mathrm{~h}$ after $1 \mathrm{st}$ administration) in case of three times a day administration

the urine tended to increase after administration of $800 \mathrm{mg}$ in a single dose and three doses for 1 day $/ 5$ days, although variability among patients was observed. However, taking into account the administered dose of investigational agent, the degree of increase was not significant. It was thought that the increase in serum aceneuramic acid concentration after administration could not be demonstrated because aceneuramic acid is excreted promptly after absorption.

The five-day treatment was initially designed with an additional dose group of $400 \mathrm{mg}$ given three times per day. However, as increases in the serum total
A

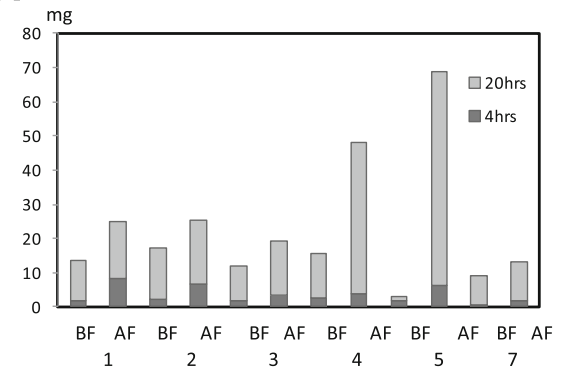

C

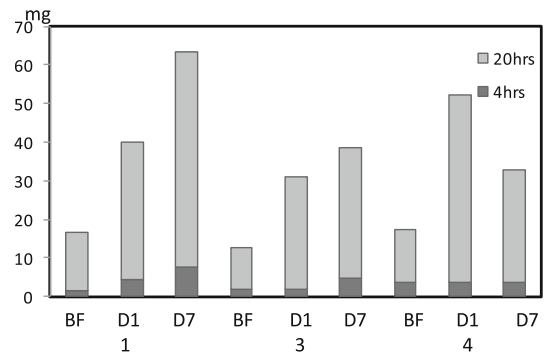

B

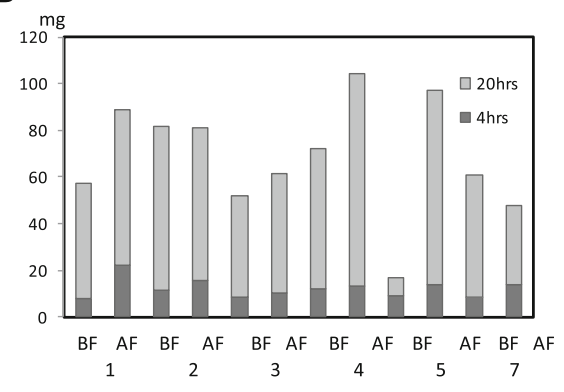

D

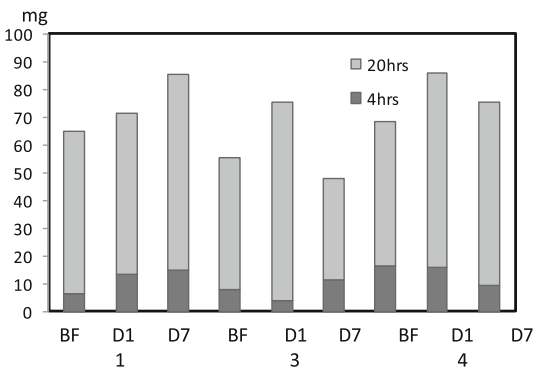

Fig. 6 Changes in urinary free and total aceneuramic acid (Trial-2). Urine was collected in periods of -24 to $20 \mathrm{~h}$ and - 20 to $0 \mathrm{~h}$ (before administration), 0 to $4 \mathrm{~h}$ and 4 to $24 \mathrm{~h}$ (after administration). Both free and total aceneuramic acid concentration in urine were measured. The amount of urinary excretion was calculated from urine concentration and its volume. The amount of free aceneuramic acid excretion in $24 \mathrm{~h}$ increased after administration. Also the amount of total aceneuramic acid excretion in $24 \mathrm{~h}$ roughly increased. a. Free aceneuramic acid with single administration (subject numbers 1 to 3 , three times per day administration (subject numbers $4,5,7$ ). b. Total aceneuramic acid with single administration (subject numbers 1 to 3, three-times-per day administration (subject numbers 4, 5, 7). c. Free aceneuramic acid with three-timesper-day for 7-day administration (subject numbers 1,3,4). d. Total aceneuramic acid with three-times-per-day for 7 days administration (subject numbers 1,3,4). BF: before administration, AF: after administration, D1: Day 1 of administration,D 7: Day 7 of administration 
Table 3 Summary of adverse events in Trial-1 and Trial-2

\begin{tabular}{|c|c|c|c|c|c|c|}
\hline \multirow[t]{2}{*}{ Preferred term } & \multicolumn{3}{|l|}{ Trial- $^{a}$} & \multicolumn{3}{|l|}{ Trial-2 } \\
\hline & $\begin{array}{l}800 \mathrm{mg} \times 1 \mathrm{n} \\
=3\end{array}$ & $\begin{array}{l}800 \mathrm{mg} \times 3 \mathrm{n} \\
=3\end{array}$ & $\begin{array}{l}800 \mathrm{mg} \times 3 \times 5 n \\
=3\end{array}$ & $\begin{array}{l}2,000 \mathrm{mg} \times 1 \mathrm{n} \\
=3\end{array}$ & $\begin{array}{l}2,000 \mathrm{mg} \times 3 \mathrm{n} \\
=3\end{array}$ & $\begin{array}{l}2,000 \mathrm{mg} \times 3 \times 7 \mathrm{n} \\
=3\end{array}$ \\
\hline Subjects with any $A E, n(\%)$ & $3(100)$ & $3(100)$ & $3(100)$ & $1(33.3)$ & $2(66.7)$ & $2(66.7)$ \\
\hline The number of AEs, $n$ & 14 & 17 & 22 & 1 & 3 & 2 \\
\hline Blood albumin decreased & $1(33.3)$ & $2(66.7)$ & $3(100)$ & & & \\
\hline Protein total decreased & $2(66.7)$ & $1(33.3)$ & $2(66.7)$ & & & \\
\hline Haematcrit decreased & $1(33.3)$ & $2(66.7)$ & $1(33.3)$ & & & \\
\hline Protein urine present & $2(66.7)$ & & $1(33.3)$ & & & \\
\hline Albumin globulin ratio decreased & & $2(66.7)$ & $1(33.3)$ & & & \\
\hline Platelet count decreased & $1(33.3)$ & $1(33.3)$ & & & & \\
\hline Blood cholinesterase Increased & $1(33.3)$ & & $1(33.3)$ & & & \\
\hline Blood phosphorus increased & $1(33.3)$ & & $1(33.3)$ & & & \\
\hline Blood urea decreased & $1(33.3)$ & & $1(33.3)$ & & & \\
\hline Specific gravity urine Increased & $1(33.3)$ & & $1(33.3)$ & & & \\
\hline Blood potassium decreased & & $1(33.3)$ & $1(33.3)$ & & & \\
\hline Red blood cell count decreased & & $1(33.3)$ & $1(33.3)$ & & & \\
\hline Blood urine present & & $1(33.3)$ & $1(33.3)$ & & & \\
\hline eczema & & & & $1(33.3)$ & & \\
\hline Blood triglycerides increased & & & & & $2(66.7)$ & $1(33.3)$ \\
\hline $\begin{array}{l}\text { Blood lactate dehydrogenase } \\
\text { increased }\end{array}$ & & & & & $1(33.3)$ & \\
\hline Fall & & & & & & $1(33.3)$ \\
\hline
\end{tabular}

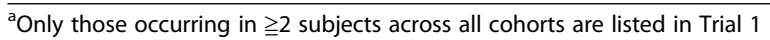

aceneuramic acid concentration with the administration of up to three times/day were not observed, considering the review of the Data and Safety Monitoring Committee, we decided to examine the administration of $800 \mathrm{mg}$ doses given three times/day for 5 days. We chose a single dose of $800 \mathrm{mg}$ after finding that there were no abnormalities that might be major problems when we administered single oral doses of $5000 \mathrm{mg} / \mathrm{kg}$ to mice and rats [22], which was equivalent to a dose that was 375 times as strong as the initial dose of $800 \mathrm{mg}$ (based on calculations using a body weight of $60 \mathrm{~kg}$ ), and so we believed that there would be no problem of safety. Studies of model mice confirmed that a dosage of $20 \mathrm{mg} / \mathrm{kg}$ per day was effective to prevent onset of the disease [20]. Doses of $800 \mathrm{mg}$ each time or $2400 \mathrm{mg}$ per day are nearly equivalent to or are a multiple of this dosage (based on calculations using a body weight of $60 \mathrm{~kg}$ ). Other relevant factors included that it is a component that exists in the body and is constantly ingested with food to a certain degree. Furthermore, it was understood that toxicity was low based on toxicity studies (teratogenicity in rats [23], genotoxicity tests [24-26], a core battery of safety pharmacology studies including hERG test [27-29]) and ongoing chronic toxicity studies in rats [27] and in dogs [30]). Also, it is estimated that the number of patients in Japan that have the disease that may be treated with this drug is no more than around 400. At the time that we conducted both trials we only knew of 100 patients in Japan, and even as we write this the total is not even 200 patients. We performed the best trial that we could under the limitation of having 6 trial subjects.

In Trial-1, patients' serum total aceneuramic acid concentrations before commencement of administration were at the same level as in individuals without GNE Myopathy (reference value: 440 to $710 \mu \mathrm{g} / \mathrm{mL}$ ) as was already known, while it was also known that the concentration in the muscular tissues is decreased [31]. Patients with GNE myopathy maintain synthetic capacity of aceneuramic acid, although the capacity is reduced [31], and thus, the difference in the distribution of the synthesizing enzyme depending on tissues [11,32] could lead to muscle-specific pathological conditions and differences in degree of disabilities depending on the muscles affected. The causative gene underlying this disease is the GNE gene, and it is considered highly probable that one of the onset mechanisms may be due to the abnormalities of glycoprotein and glycolipid caused by decreased synthetic capacity for aceneuramic acid. However, the discussion remains as to whether it is a 
loss-of-function mutation or a toxic gain mutation [33]. Furthermore, in Trial-1, we measured $N$-glycolylneuraminic acid, which is said to not be synthesized in human body [33], and all measurements were below the detection limit.

We were unable to confirm an increase in serum concentrations in Trial-1 which used conventional tablets and measured total aceneuramic acid, and therefore Trial-2 was performed using and comparing the trial outcomes from overseas. Using $500 \mathrm{mg}$ extended-release tablets, which has been used for patients with GNE myopathy in the United States, $2000 \mathrm{mg}$ of aceneuramic acid was administered in a single dose and three doses per day for 1 day/7 days. $2000 \mathrm{mg} 3$ times in 1 day is the clinical dose for an overseas comparative trial. In this trial the dosage amount was selected to confirm whether it would be alright to administer the same dosage as was used overseas for the clinical dosage to conduct the next phase long-term dosage trials. Then serum free aceneuramic acid concentration was measured as well as confirmation of the safety, and the amount of total and free aceneuramic acid excreted in the urine was calculated by measurement of the volume of urine and the total and free aceneuramic acid concentrations in the urine. Six patients participated in Trial-2, and two patients who received the single dose and one patient who received the three doses per day also participated in the seven-day administration.

With regards to serum free aceneuramic acid concentration, it was almost the same as that of the overseas Phase I trial when without administration [34], and all nine cases, including three patients given the single dose, three doses per day, and three doses per day for 7 days, showed obvious increases in concentration after administration.

In the mean value for the three patients given the $2000 \mathrm{mg}$ dose three times/day, the value of first peak was approximately more than twice that without treatment, and a higher value than the first peak was maintained at $24 \mathrm{~h}$ after administration. The results suggested that the increase in serum free aceneuramic acid concentration as a result of the administration of the $2000 \mathrm{mg}$ dose given three times/day was maintained for a whole day.

With the seven-day administration, the mean value of serum free aceneuramic acid concentration in three patients was at about 2.8 times that of the baseline (before administration), and it was maintained from the second day of administration to the following morning of the final day of administration. A peak in trough value was observed within 7 days for all three patients, suggesting that the concentration levels with longer-term administration would not be extremely increased beyond the levels observed in these 7 days. On day 7 of administration, the concentration of serum free aceneuramic acid was about 2.4 times on average that of before the start of treatment.

The amount of free aceneuramic acid excreted in the urine increased compared to pretreatment for all nine measurements, including those given a single dose, three doses per day for 1 day/7 days. The amount of total aceneuramic acid excreted in the urine also generally increased, indicating that the investigational agent was absorbed into the body.

As stated above, with extended-release tablets being used for trials in overseas, increases in serum free aceneuramic acid concentration of two to three times that of without treatment were observed in Trial-2. The results are consistent with the overseas trials [35, 36]. Thus, a long-term clinical trial to verify the efficacy and safety can be conducted in Japan as well, with the same dosing regimen as was used overseas. In the present trial, serum free aceneuramic acid concentration and the amount of free aceneuramic acid excreted in the urine were increased in all patients after administration of the investigational agent. On the basis of the outcomes of a trial that examined the pharmacokinetics in rats, it is expected that aceneuramic acid absorbed via oral administration is partly excreted as aceneuramic acid, and partly transferred to muscle tissue and produces the effect. The efficacy has been demonstrated in mouse-model implanted mutations commonly seen in Japanese patients [36], and a phase II trial conducted overseas also indicated the efficacy [35], therefore, we believed that similar efficacy can be expected in Japanese patients.

With regards to safety, all stages of the two trials were completed without withdrawal of any patient. A total of 53 adverse events were observed in Trial-1 with conventional tablets; however, all events were not severe and a causal relationship with the investigational agent was ruled out. In Trial-2 with extended-release tablets, adverse events occurred in one out of three patients given a single dose, two out of three patients given three doses per day for 1 day, and two out of three patients given three doses per day for 7 days. However, all events were mild, and the causal relationships with the investigational agent were deemed to be 'no relationship'. In both studies the causal relationships with investigational agents were judged by the doctors in charge, based on patients' existing illnesses, disease complications, and overall condition of the patients (for example, because falls occur frequently in this disease, a fall was judged "no relationship" in one case).Thus, there were no findings that would pose a particular problem for safety in the present trial. The reason that there were fewer adverse events in Trial-2 compared to Trial-1 was that all laboratory test value abnormalities, even 
with no clinical problems, were included as adverse events in Trial-1, whereas adverse events were limited to those that posed clinical problems in Trial-2.

In Trial-1, the following abnormalities in the clinical laboratory tests were observed; decreased serum albumin in six cases, decreased total protein in five cases, decreased hematocrit levels in four cases, decreased albumin-globulin ratio and positive results in urine protein in three cases each, decreased red cell count, decreased blood platelet count, increased serum cholines terase, decreased blood urea, decreased blood potassium, increased blood phosphorus, increased urine specific gravity, and positive results in uric blood in two cases each. These changes had no clinical importance and causal relationships with the investigational agent were unlikely to be defined. It was thus inferred that the changes in clinical tests were caused by various factors due to the participation in the trial, such as changes in life style and environment, influences of tests and blood collection. Nonetheless, careful observation of changes in those clinical findings is needed in future clinical trials. With regards to decreased platelet count, there is a report that assumed that sialic acid may play a significant role for platelets based on a case of sisters with thrombocytopenia [37]. However, no exacerbation of platelet count that could be clinical issues were observed as a result of aceneuramic acid administration in the present trial.

Kakkis et al. announced the results of their Phase I trial using extended-release tablets at the World Muscle Society of 2012 [34]. The results of our trial also demonstrated the consistent results with their trial in pharmacokinetics and safety in the Asian population. GNE myopathy is known to frequently occur in Jewish people, and thus there are many patients in Middle Eastern countries such as Israel, and in the United States; however, many patients are also found in Asian countries including Japan, Korea, and China. The fact that no difference was found in terms of pharmacokinetics and safety is not a particular problem in developing the treatment in the Asia region.

The present report describes the pharmacokinetics of aceneuramic acid in detail, and we believe that the report provides important fundamental knowledge for trials from now on, in determining therapeutic effects and subsequent clinical use of the agent.

\section{Conclusion}

The elevated serum concentration of aceneuramic acid and safety were confirmed. We decided that the trial can shift to the next level to examine the long-term efficacy and safety for Japanese patients as well.

\section{Additional files}

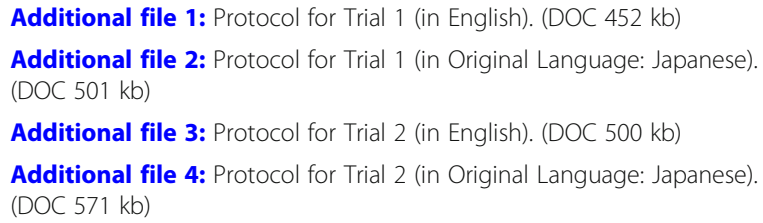

Additional file 3: Protocol for Trial 2 (in English). (DOC 500 kb)

Additional file 4: Protocol for Trial 2 (in Original Language: Japanese). (DOC $571 \mathrm{~kb}$ )

\section{Funding}

This study was supported by Grants for Innovation Promoting Project from New Energy and Industrial Technology Development Organization ( $\mathrm{H} 21$ shineneken0812002); the grant on Research on Rare and Intractable Diseases (H26-intractable disease 037 and 082) from the Ministry of Health, Labour and Welfare of Japan; the Ministry of Health, Labour and Welfare of Japan (H21-nanchi-ippan-024, H22-nanchi-ippan-117, H24-nanchi-ippan-028, H26nanchitou(nan)-ippan-079); Health and Labour Sciences Research Grants for Comprehensive Research on Persons with Disabilities from Japan Agency for Medical Research and Development (15Adk0310043h0002); Grants-in-Aid for research on rare and intractable diseases; and Grant-in-Aid for Challenging Exploratory Research (26670436) and Translational Research Network Program from the Japanese Ministry of Education, Culture, Sports, Science and Technology. The drugs were provided by Nobelpharma Co., Ltd..

\section{Availability of data and materials}

The datasets used and/or analyzed during the current study are available from MA on reasonable request.

\section{Authors' contributions}

NS, MK, HW, RI, MT, HK, RA, AS, and MA examined patients. RA and TY completed the statistical analysis. IN and MA approved the study design and supervised the work progression. NS and MA wrote the manuscript. All authors read and approved the final manuscript.

\section{Ethics approval and consent to participate}

The study protocol (including patient sample collection) was approved by the ethics committee of Tohoku University Hospital. Informed consent was obtained from all patients.

Consent for publication

Not applicable.

\section{Competing interests}

The authors declare that they have no competing interests.

\section{Publisher's Note}

Springer Nature remains neutral with regard to jurisdictional claims in published maps and institutional affiliations.

\section{Author details}

${ }^{1}$ Department of Neurology, Tohoku University Graduate School of Medicine, 1-1 Seiryo-machi, Aoba-ku, Sendai 980-8574, Japan. ${ }^{2}$ Clinical Research Center, Gifu University Hospital, Gifu, Japan. ${ }^{3}$ Clinical Research, Innovation and Education Center, Tohoku University Hospital, Sendai, Japan. ${ }^{4}$ Division of Biostatistics, Tohoku University Graduate School of Medicine, Sendai, Japan. ${ }^{5}$ Department of Neuromuscular Research, National Institute of Neuroscience and Department of Genome Medicine Development, Medical Genome Center, National Center of Neurology and Psychiatry (NCNP), Kodaira, Japan.

Received: 10 May 2018 Accepted: 30 August 2018

Published online: 06 September 2018

\section{References}

1. Huizing M, Krasnewich DM. Hereditary inclusion body myopathy: a decade of progress. Biochim Biophys Acta. 2009;1792:881-7.

2. Nishino I, Carrillo-Carrasco N, Argov Z. GNE myopathy: current update and future therapy. J Neurol Neurosurg Psychiatry. 2015;86:385-92. 
3. Mori-Yoshimura M, Hayashi YK, Yonemoto N, Nakamura H, Murata M, Takeda S, Nishino I, Kimura E. Nationwide patient registry for GNE myopathy in Japan. Orphanet J Rare Dis. 2014;9:150.

4. Mori-Yoshimura M, Oya Y, Hayashi YK, Noguchi S, Nishino I, Murata M. Respiratory dysfunction in patients severely affected by GNE myopathy (distal myopathy with rimmed vacuoles). Neuromuscul Disord. 2013;23:84-8.

5. Mori-Yoshimura M, Oya Y, Yajima H, Yonemoto N, Kobayashi Y, Hayashi YK, Noguchi S, Nishino I, Murata M. GNE myopathy: a prospective natural history study of disease progression. Neuromuscul Disord. 2014;24:380-6.

6. Nonaka I, Sunohara N, Ishiura S, Satoyoshi E. Familial distal myopathy with rimmed vacuole and lamellar (myeloid) body formation. J Neurol Sci. 1981;51:141-55.

7. Nonaka I, Sunohara N, Satoyoshi E, Terasawa K, Yonemoto K. Autosomal recessive distal muscular dystrophy: a comparative study with distal myopathy with rimmed vacuole formation. Ann Neurol. 1985;17:51-9.

8. Argov Z, Yarom R. "rimmed vacuole myopathy" sparing the quadriceps. A unique disorder in Iranian Jews. J Neurol Sci. 1984;64:33-43.

9. Mitrani-Rosenbaum S, Argov Z, Blumenfeld A, Seidman CE, Seidman JG. Hereditary inclusion body myopathy maps to chromosome 9p1-q1. Hum Mol Genet. 1996;5:159-63.

10. Eisenberg I, Avidan N, Potikha T, Hochner H, Chen M, Olender T, Barash M, Shemesh M, Sadeh M, Grabov-Nardini G, et al. The UDP-Nacetylglucosamine 2-epimerase/N-acetylmannosamine kinase gene is mutated in recessive hereditary inclusion body myopathy. Nat Genet. 2001;29:83-7.

11. Hinderlich S, Stasche R, Zeitler R, Reutter W. A bifunctional enzyme catalyzes the first two steps in $\mathrm{N}$-acetylneuraminic acid biosynthesis of rat liver. Purification and characterization of UDP-N-acetylglucosamine 2-epimerase/ N-acetylmannosamine kinase. J Biol Chem. 1997;272:24313-8.

12. Stasche R, Hinderlich S, Weise C, Effertz K, Lucka L, Moormann P, Reutter W. A bifunctional enzyme catalyzes the first two steps in $\mathrm{N}$-acetylneuraminic acid biosynthesis of rat liver. Molecular cloning and functional expression of UDP-N-acetyl-glucosamine 2-epimerase/N-acetylmannosamine kinase. J Biol Chem. 1997;272:24319-24.

13. Arai A, Tanaka K, Ikeuchi T, Igarashi S, Kobayashi H, Asaka T, Date H, Saito M, Tanaka H, Kawasaki S, et al. A novel mutation in the GNE gene and a linkage disequilibrium in Japanese pedigrees. Ann Neurol. 2002;52:516-9.

14. Nishino I, Noguchi S, Murayama K, Driss A, Sugie K, Oya Y, Nagata T, Chida K, Takahashi T, Takusa Y, et al. Distal myopathy with rimmed vacuoles is allelic to hereditary inclusion body myopathy. Neurology. 2002;59:1689-93.

15. Tomimitsu H, Ishikawa K, Shimizu J, Ohkoshi N, Kanazawa I, Mizusawa H. Distal myopathy with rimmed vacuoles: novel mutations in the GNE gene. Neurology. 2002;59:451-4.

16. Tomimitsu H, Shimizu J, Ishikawa K, Ohkoshi N, Kanazawa I, Mizusawa H. Distal myopathy with rimmed vacuoles (DMRV): new GNE mutations and splice variant. Neurology. 2004;62:1607-10.

17. Celeste FV, Vilboux T, Ciccone C, de Dios JK, Malicdan MC, Leoyklang P, McKew JC, Gahl WA, Carrillo-Carrasco N, Huizing M. Mutation update for GNE gene variants associated with GNE myopathy. Hum Mutat. 2014;35:915-26.

18. Huizing M, Carrillo-Carrasco N, Malicdan MC, Noguchi S, Gahl WA, MitraniRosenbaum S, Argov Z, Nishino I. GNE myopathy: new name and new mutation nomenclature. Neuromuscul Disord. 2014;24:387-9.

19. Malicdan MC, Noguchi S, Nonaka I, Hayashi YK, Nishino I. A GNE knockout mouse expressing human GNE D176V mutation develops features similar to distal myopathy with rimmed vacuoles or hereditary inclusion body myopathy. Hum Mol Genet. 2007;16:2669-82.

20. Malicdan MC, Noguchi S, Hayashi YK, Nonaka I, Nishino I. Prophylactic treatment with sialic acid metabolites precludes the development of the myopathic phenotype in the DMRV-hIBM mouse model. Nat Med. 2009;15:690-5.

21. Nohle U, Schauer R. Uptake, metabolism and excretion of orally and intravenously administered, 14C-and 3H-labeled $\mathrm{N}$-acetylneuraminic acid mixture in the mouse and rat. Hoppe Seylers Z Physiol Chem. 1981;362:1495-506.

22. Hatanaka K, Nakajima N, Hanabusa T. Acute Toxicity Test of Sodium 5(acetylamino)- 3,5- dideoxy- D- glycero-D- galacto- 2- nonulosonate (KI-111) in Mice and Rats. Kiso to Rinsho (In Japanese). 1987;21:137-41.

23. Mitsubishi-Chemical-Medience: Oral Embryo-Fetal Development Study of NAcetylneuraminic Acid in Rats (Study P100197)(In-house document).
24. Midorikawa H, Hanabusa T, Mitomi M, Ogasawara S. Reverse Mutation Tests of Sodium 5- (acetylamino)- 3,5- dideoxy- D- glycero-D- galacto- 2 nonulosonate (Kl-111) Using S. typhimurium and E. coli. Kiso to Rinsho (In Japanese). 1987:21:147-51.

25. Hanafusa T, Mitomi M, Ogasawara S. Chromosomal Aberration Test of Sodium 5- (acetylamino)- 3,5- dideoxy- D- glycero-D- galacto- 2nonulosonate (Kl-111) with Cultured Mammalian Cell. Kiso to Rinsho (In Japanese). 1991;25:199-203.

26. Yamashita H, Saito F, Hanafusa T, Mitomi M, Ogasawara S. Studies on Antigenicity of Sodium 5- (acetylamino)- 3,5- dideoxy- D- glycero-D- galacto2- nonulosonate (KI-111). Kiso to Rinsho (In Japanese). 1991;25:189-97.

27. Mitsubishi-Chemical-Medience: 26 week repeated oral dose toxicity test of $\mathrm{N}$-acetylneuraminic acid in rats (Study No. P100196)

28. Mitsubishi-Chemical-Medience: Safety Pharmacological Study of NAcetylneuraminic Acid (Study P100534) (In-house document).

29. Mitsubishi-Chemical-Medience: Safety Pharmacology Study of NAcetylneuraminic Acid: Effects on hERG Current (Study P100536) (In-house document).

30. Mitsubishi-Chemical-Medience: 39 Week Repeated Oral Dose Toxicity Test and 4 Week Recovery Test of N-actylneuraminic Acid in Dogs (Study No. P100508). (In-house document).

31. Noguchi S, Keira Y, Murayama K, Ogawa M, Fujita M, Kawahara G, Oya Y, Imazawa M, Goto Y, Hayashi YK, et al. Reduction of UDP-Nacetylglucosamine 2-epimerase/N-acetylmannosamine kinase activity and sialylation in distal myopathy with rimmed vacuoles. J Biol Chem. 2004; 279:11402-7.

32. Lucka L, Krause M, Danker K, Reutter W, Horstkorte R. Primary structure and expression analysis of human UDP-N-acetyl-glucosamine-2-epimerase/Nacetylmannosamine kinase, the bifunctional enzyme in neuraminic acid biosynthesis. FEBS Lett. 1999;454:341-4.

33. Bosch-Morato M, Iriondo C, Guivernau B, Valls-Comamala V, Vidal N, Olive M Querfurth H, Munoz FJ. Increased amyloid beta-peptide uptake in skeletal muscle is induced by hyposialylation and may account for apoptosis in GNE myopathy. Oncotarget. 2016;7:13354-71.

34. Kakkis E, Maurer M, Shah P, Donikyan M, Ahmed R. T.P.13 a phase 1 safety and pharmacokinetic study of sialic acid-extended release tablets in patients with hereditary inclusion body myopathy (HIBM or GNE myopathy). Neuromuscul Disord. 2012;22:850

35. Argov Z, Caraco Y, Lau H, Pestronk A, Shieh PB, Skrinar A, Koutsoukos T, Ahmed R, Martinisi J, Kakkis E. Aceneuramic acid extended release administration maintains upper limb muscle strength in a 48-week study of subjects with GNE myopathy: results from a phase 2, randomized, controlled study. J Neuromuscul Dis. 2016;3:49-66.

36. Yonekawa T, Malicdan MC, Cho A, Hayashi YK, Nonaka I, Mine T, Yamamoto T, Nishino I, Noguchi S. Sialyllactose ameliorates myopathic phenotypes in symptomatic GNE myopathy model mice. Brain. 2014;137:2670-9.

37. Izumi R, Niihori T, Suzuki N, Sasahara Y, Rikiishi T, Nishiyama A, Nishiyama S, Endo K, Kato M, Warita H, et al. GNE myopathy associated with congenital thrombocytopenia: a report of two siblings. Neuromuscul Disord. 2014;24: $1068-72$

Ready to submit your research? Choose BMC and benefit from

- fast, convenient online submission

- thorough peer review by experienced researchers in your field

- rapid publication on acceptance

- support for research data, including large and complex data types

- gold Open Access which fosters wider collaboration and increased citations

- maximum visibility for your research: over $100 \mathrm{M}$ website views per year

At $\mathrm{BMC}$, research is always in progress.

Learn more biomedcentral.com/submissions 